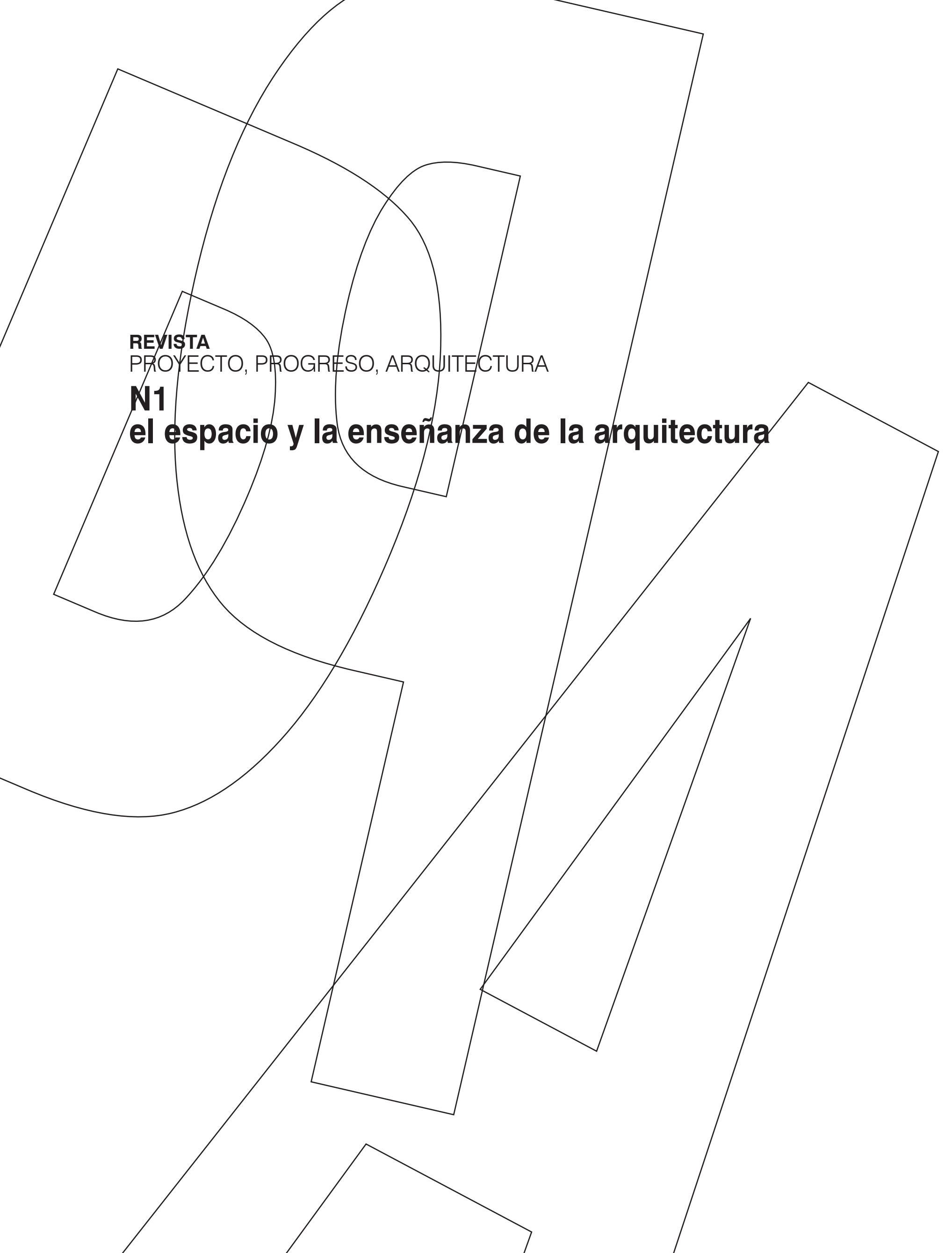


RESUMEN Revisando la Bauhaus desde su consolidación y su clímax en Dessau, se enuncia la necesidad de hacer una observación más detenida de esta arquitectura en su lugar y alguna consideración sobre cómo se aprovecha el edificio como instrumento didáctico. Se repasan antecedentes y sobre todo consecuentes que reconocen el edificio de Dessau como una obra ejemplar. A través de la obra de Hannes Meyer, se observan discrepancias con la idea de arquitectura de Gropius y se encuentra el enlace con la experiencia de la Holtschule Für Gestaltum en Ulm, ideada y realizada por Max Bill como soporte de un proyecto docente emprendido en el año 1950 que pretendía reanimar en Alemania el espíritu de la Bauhaus, truncado por la Segunda Guerra Mundial. La escuela de Ulm empezó a funcionar en 1955, al tiempo que se construía su edificio. En pocos años la polémica entre artistas y técnicos provocó el abandono de Max Bill en 1957. A duras penas, la HfG sobrevivió hasta 1968. El edificio sí ha permanecido.

PALABRAS CLAVE Arquitectura moderna; escuelas de arquitectura; espacio docente; Bauhaus; Hochschule für Gestaltum de Ulm; Max Bill

SUMMARY In reviewing the Bauhaus, from its consolidation and its climax in Dessau, there is a need to formulate a more lengthy observation of this architecture and to recognize how the building was used as a didactic instrument. Histories may be revised, but they consistently recognize the Dessau building as an exemplary work. Discrepancies with Gropius's idea of architecture are seen through the work of Hannes Meyer and the link is found with the experience of the Holtschule für Gestaltum (HfG - School of Design) in UIm. This school was devised and executed by Max Bill in support of an educational project, undertaken in 1950, that tried to reanimate the spirit of the Bauhaus in Germany, which had been cut short by World War II. The Ulm school started operations in 1955 when the building was constructed. Within a few years, the controversy between artists and technicians caused the departure of Max Bill in 1957. With great difficulty, the HfG survived until 1968. The building has survived.

KEY WORDS Modern architecture; architecture schools; educational space; Bauhaus; Hochschule für Gestaltum de Ulm; Max Bill

Persona de contacto / Corresponding author: rabajas@us.es 


\title{
LA BAUHAUS, DE DESSAU A ULM: ENSAYOS SOBRE EL ESPACIO DOCENTE DE ALTO RENDIMIENTO
} THE BAUHAUS, FROM DESSAU TO ULM: ESSAYS ON THIS HIGH YIELD EDUCATIONAL SPACE

Rosa María Añón Abajas

\begin{abstract}
Atrapados en la situación imposible de tener que adaptar el plan de estudios al tiempo disponible de enseñanza, hoy por hoy insuficiente, las facultades se dividen entre "humanidades" y "técnicas", y ambos grupos son excluyentes entre sí... Se supone que Lyautey dijo: "cuando elijo entre $A+B$ seguramente elegiré $A+B$ " en cualquier caso, este dilema no existe si el tiempo disponible para una instrucción correcta es suficiente. Sin embargo, lejos de estar resuelta, la situación ha empeorado, sobre todo tras la llegada de otros grupos poderosos que favorecen la "masificación" de la profesión -es decir, aquellos tecnócratas que consideran a la arquitectura como otra mercancía más-. Para ellos es un imperativo reducir más aún la duración de nuestros estudios, para así producir una explosión demográfica e incrementar el número de arquitectos más allá de la capacidad del mercado... Por primera vez en la historia generaciones de arquitectos están saliendo de las universidades europeas peor preparados que sus antecesores... paradójicamente al intentar crear arquitectos más competitivos, solo estamos produciendo arquitectos menos competentes.
\end{abstract}

Rafael de la Hoz, $1993^{1}$

mplazados de nuevo a reformar los planes de E estudio de Arquitectura, obligados por la directiva de Bolonia y el compromiso de convergencia europea, la polémica es inevitable. Multitud de razonamientos contradictorios han saturado los foros y la prensa. Analizar este enmarañado debate requiere un tiempo excesivo - la masa crítica tiene algunos inconvenientes-. Buscando otros modos de contribuir, parece oportuno revisar algunos hechos acontecidos en parecidas circunstancias de intensa demanda de cambios profundos; momentos en que también fue unánime el acuerdo sobre la necesidad de innovación y renovación, y cuyo análisis muestra que la experimentación y el ensayo serio sólo son viables con recursos suficientes, que permitan arriesgar con seguridad, chequeando cada hipótesis mediante ensayos y prototipos, antes de aplicarse precipitadamente de forma generalizada.

Aunque ciertamente no sea imprescindible que concurran las actuales circunstancias para justificar la pertinencia de este artículo, el actual contexto refresca en nuestra memoria el ejemplo de la Bauhaus y hace oportuna una revisión de su legado en la que se incida sobre todo en sus consecuencias. El principal objetivo de este artículo es comprender mejor la arquitectura de la HfG de Ulm, obra que considero insuficientemente explicada por la bibliografía existente hasta el momento. Recurriendo a relacionarla con otras arquitecturas conocidas, antecedentes y consecuentes, se reivindica como una obra que participa activamente del debate arquitectónico de su tiempo y como una experiencia que resulta decisiva en el desarrollo de la arquitectura de las décadas posteriores, que está presente y contenida en ellas.

\section{LA BAUHAUS EN DESSAU, RAZÓN, INTENCIÓN Y CONSECUENCIAS}

Todos conocemos mejor o peor la Bauhaus de Gropius y sus desplazamientos entre Weimar, Dessau y finalmente Berlín; su historia está ampliamente estudiada y documentada; sin embargo no han trascendido muchas reflexiones sobre la vigencia que pueden continuar teniendo sus programas para la formación del arquitecto en la actualidad, o sobre el papel que desempeñó en toda aquella aventura la producción experimental realizada desde la propia escuela.

El edificio de la Bauhaus en Dessau, tan profusamente divulgado, admirado y añorado, carece de suficientes dibujos comprometidos con su análisis y en particular sobre uno de sus valores principales como es el control territorial que ejerce en el desarrollo urbano². Para esto hace falta una representación que busque revelar la relación con

1. DE LA HOZ, R. Dependa est Architectura. Conferencia ofrecida en la Convención AIA/UIA, Chicago 1993; y en la Bienal de Arquitectura de Buenos Aires, en septiembre del mismo año.

2. Lo afirmado se puede verificar examinando la bibliografía sobre el edificio. Se recomienda ver WESTON, R.: Plans, sections and elevations : key buildings of the twentieth. London : King, 2004. 
N1_EL ESPACIO Y LA ENSEÑANZA DE LA ARQUITECTURA

28
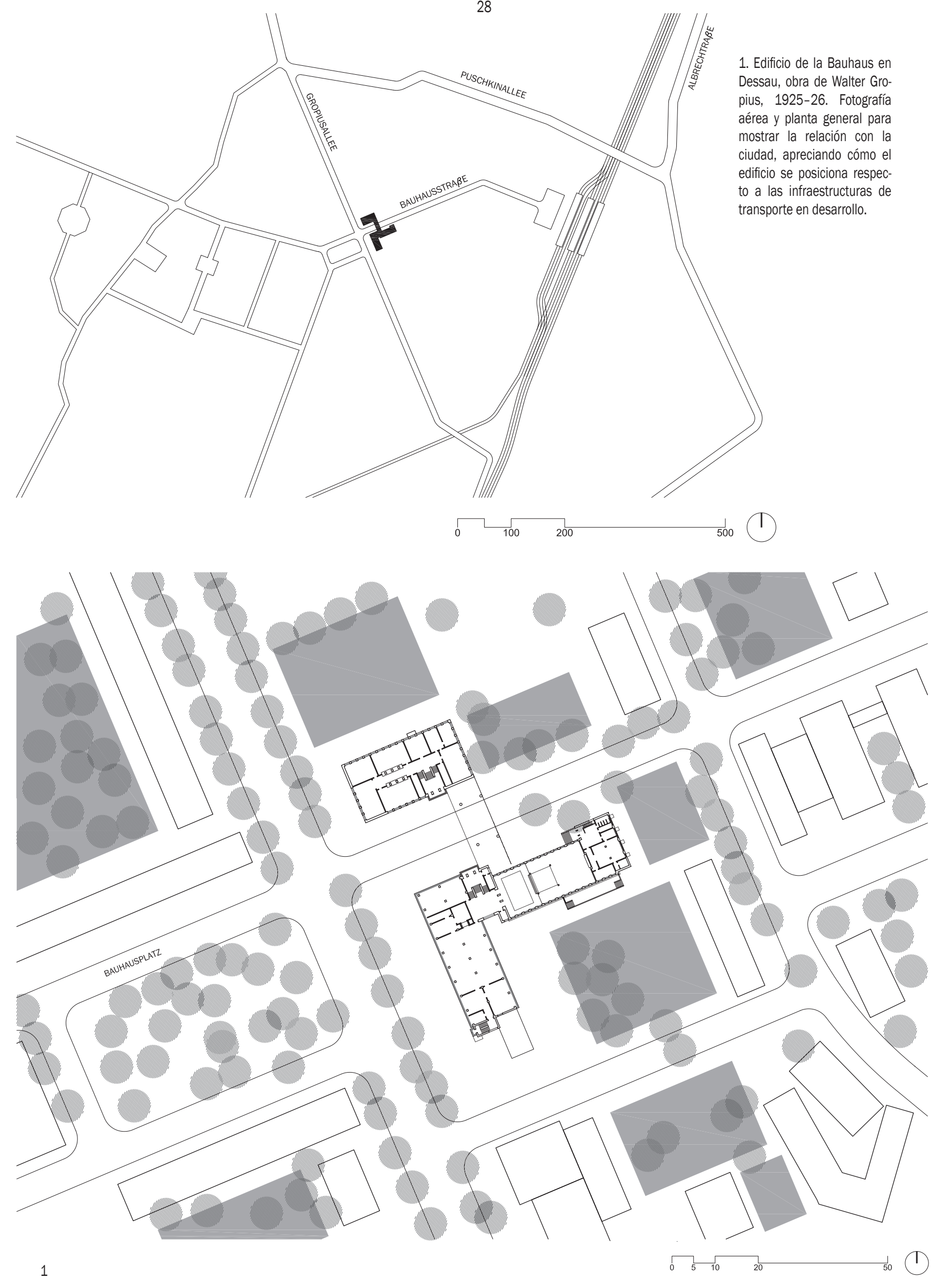
la ciudad y permita apreciar cómo desde el proyecto, el edificio se posiciona en relación a las principales infraestructuras territoriales, condicionando el posterior desarrollo y creando un espacio urbano cualificado. Este artículo aporta un dibujo (figura 1) con la intención de transmitir y demostrar cómo esta arquitectura participa y activa el lugar en que se implica, sin que ello merme la idoneidad de su solución funcional sino por el contrario, la multiplique; porque la estrategia del proyecto aprovecha la interacción y la superposición de todos los objetivos perseguidos, en un ensayo interesadísimo por demostrar el potencial de la arquitectura funcional moderna para construir no sólo habitaciones confortables, sino también ciudades funcionales y paisajes urbanos amables.

Dessau se encuentra al sur del Elba, río cuyo cauce en este tramo, evoluciona de este a oeste. En Dessau convergen carreteras principales en sentido norte-sur y este-oeste; la entrada desde el norte a la ciudad se transforma en la avenida principal Albrechstra $\beta$ e. El trazado ferroviario atraviesa Dessau en paralelo a la Albrechstra $\beta$ e, construyendo un límite al oste de la ciudad, que al estar también limitada al este por el río Mulbe, afluente del Elba, se desarrolla principalmente hacia el norte y el sur.

Al oeste del corredor ferroviario se encuentra el parque de Georgengarten y la vecina localidad de Ziebigk, donde se establece la Bauhaus. La relación con Dessau queda establecida por la Puschkinalle, que cuenta con un paso elevado sobre las vías ferroviarias; la estación de Dessau se localiza muy cerca, al sur de este viaducto. Más al sur hay otro paso elevado sobre el ferrocarril donde convergen la Künhauerstra $\beta$ e en dirección este-oeste y la Gropiusstrallee en dirección diagonal, hacia el noroeste.

El edificio de la Bauhaus se sitúa en el punto medio de la Gropiusstra $\beta$ e, dando frente a la Bauhausplatz, desde donde parte hacia el oeste la Fischereiweg; también ofrece la continuidad a ese eje en dirección hacia el este mediante la Bauhausstraße que pasando bajo la galería de oficinas de la Bauhaus, se prolonga hasta confluir con el paso del corredor ferroviario en un punto muy próximo a la estación donde también converge el eje principal de Georgengarten. Actualmente la Bauhausstra $\beta$ e es el eje principal del campus universitario. Por lo tanto, funciona como germen del campus niversitario y como puerta de encuentro de la red de infraestructuras metropolitanas y la red de circulación local de carácter más doméstico y muchas veces peatonal. Se configura como un edificio único aunque con varios cuerpos reconocibles y claramente diferenciados por su volumen y su materialización.

Enfrentando el instituto de arte con la escuela de arte, se significa con claridad su diferencia y una relación exclusivamente administrativa; ambos edificios se conectan por la característica galería elevada de oficinas y despachos que dan servicio a ambas instituciones. La emblemática escuela de arte se distingue sobre todo por la singularidad de la torre de talleres, compuesta por la superposición de múltiples espacios reiterados e indiferenciados funcionalmente, construidos mediante forjados de grandes luces, con estructura de hormigón armado visto y con cerramiento ligero acristalado que además de una buena iluminación natural y ventilación, se presentaba como tecnología innovadora de gran futuro; todo esto en correspondencia con un programa experimental y cambiante. Otros usos singulares como el aula magna, el vestíbulo, el despacho del director o la torre de viviendas-estudio, defienden la necesidad de mantener la atención en cada parte, pero sin atenuar el protagonismo de los talleres. El edificio muestra un indiscutible afán propagandístico de los responsables que convencidos de los beneficios sociales que producirían la arquitectura moderna y la construcción industrial, se esmeraron por cuidar cada detalle y ofrecer una imagen impecable y atractiva, vinculada a las nuevas tecnologías (figura 2).

En efecto, el resultado fue un éxito rotundo. Otras arquitecturas contemporáneas, en algunos casos muy meritorias, nunca han llegado a ser tan conocidas, posiblemente ensombrecidas por el enorme peso del modelo de Dessau. Revisando algunos ejemplos podemos llegar a coincidir en las evidentes relaciones que se pueden apreciar. Imposible eludir las obras del arquitecto holandés Jan Duiker que fueron tan avanzadas y arriesgadas en el discurso funcionalista. Lamentablemente falleció muy joven, su obra quedó poco divulgada y puede que intencionadamente silenciada por las voces dominantes del momento. Su maestría en el manejo de materiales como el vidrio, el hierro y el hormigón, que revolucionó la forma y el lenguaje de la arquitectura contemporánea, queda indiscutiblemente probada en el sanatorio de Zonnestraal (figura 2) o la escuela al aire libre de Ámsterdam, dos de 
N1_EL ESPACIO Y LA ENSEÑANZA DE LA ARQUITECTURA
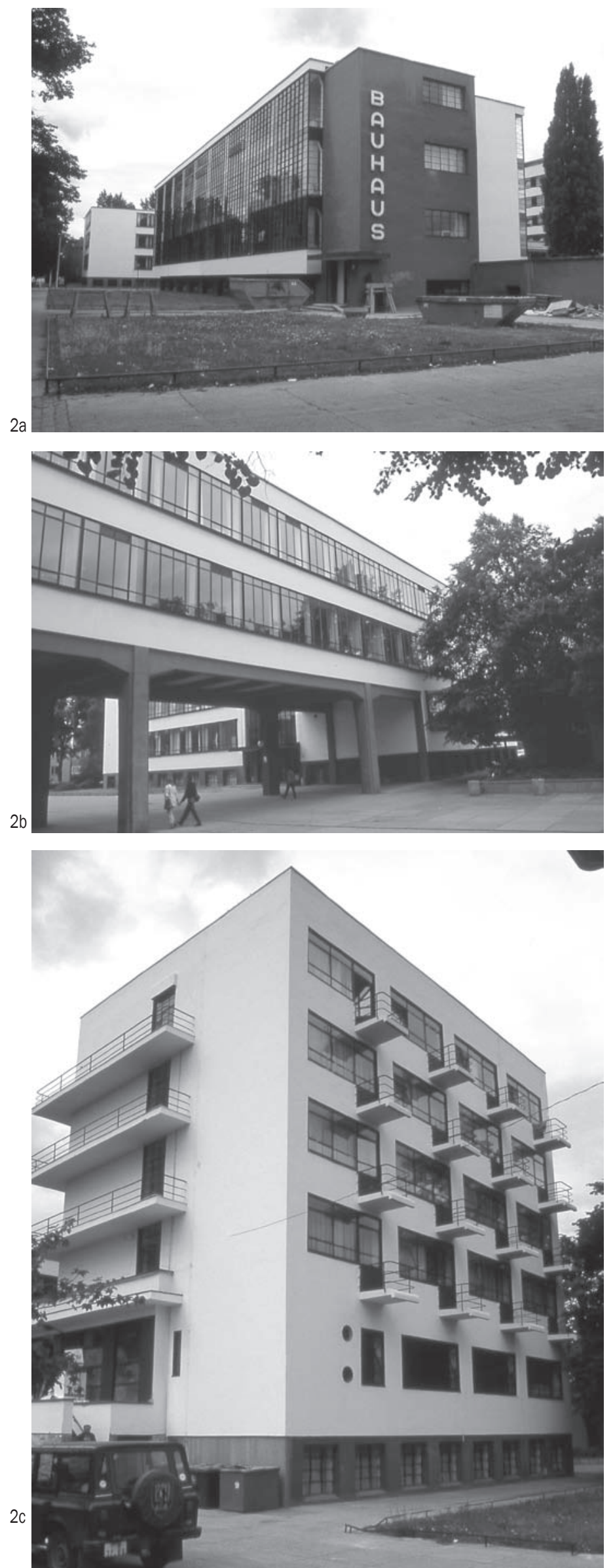

2. Escuela Bauhaus en Ziebigk-Dessau, Walter Gropius, 1925-26: edificio de talleres (2.a), pasaje bajo la galería de despachos (2.b) y torre de estudios (2.c). Sanatorio de Zoonestraal en Hilversum (1925-28). Jan Duiker y Bernhard Bijvoet (2.d)

3. Escuela Federal de Obreros Alemanes en Bernau, 1928-30. Arquitectos: Hannes Meyer y Hans Wittwer. Dibujo de planta general.

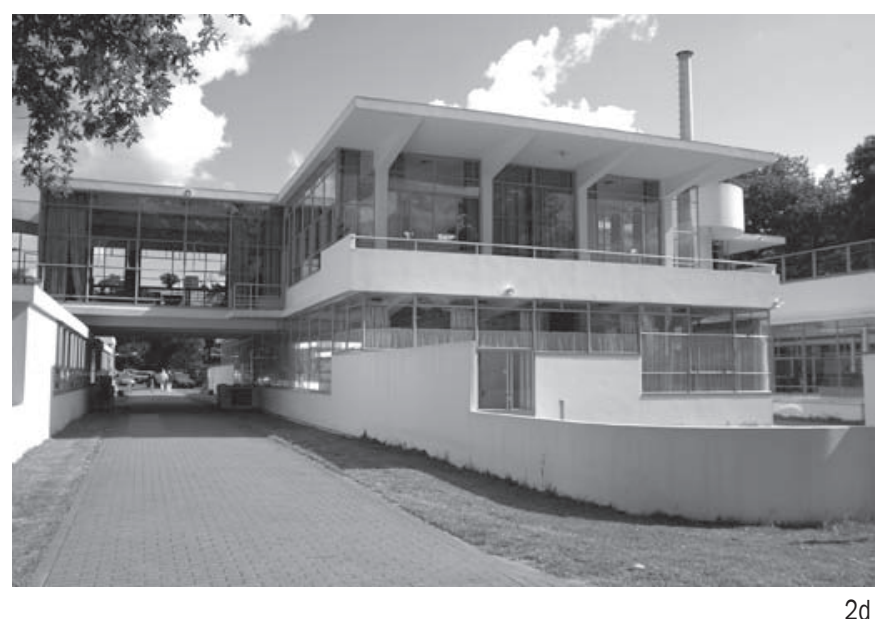




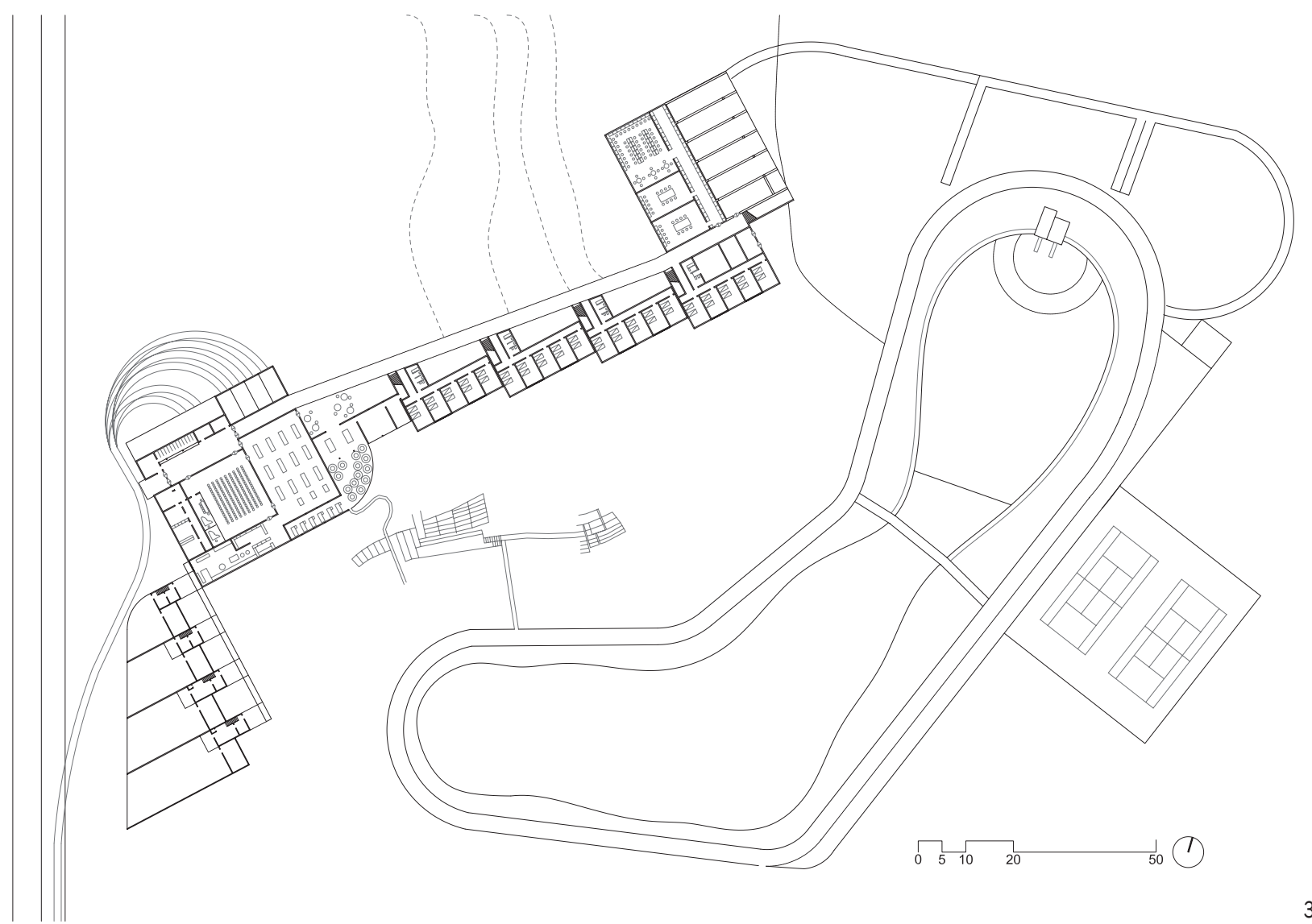

sus obras más representativas, ambas construidas simultáneamente en el tiempo con el edificio de la Bauhaus en Dessau. Sin embargo, los proyectos de Duiker son muy anteriores, ya que el primer proyecto para el sanatorio data de 1916, fecha en que resultó vencedor del correspondiente concurso ${ }^{3}$. Gropius, algo mayor que Duiker, había sido internacionalmente reconocido ya en 1911 con la fábrica Fagus, pero en 1924 todavía se ocupaba de ideas como las que refleja la oficina del director de la escuela de Weimar ${ }^{4}$, sede de la primera Bauhaus; en ambos casos se trata de obras todavía muy afectadas por formalistas pretensiones de buen gusto, muy distantes de la austeridad estructural de Duiker.

La Bauhaus cambió con frecuencia de director y de orientación. Meyer sucedió a Gropius y la escuela inició una progresiva evolución desde lo que fue una escuela de artes aplicadas a una escuela especializada en arquitectura, aunque la flamante sede de Dessau diseñada por Gropius continuó sirviendo. No obstante, la idea de arquitectura funcional de Meyer difiere claramente de la de Gropius, como evidencia su proyecto para la Escuela
Federal Bundesschule en Bernau, al norte de Berlín, encargo que recibió por parte de la Confederación General de Sindicatos Alemanes inmediatamente a su nombramiento como director de la Bauhaus en 1928 (figura 3). Se trataba de un centro destinado a cursillos intensivos de cuatro semanas para funcionarios y el programa debía ofrecer además albergue e instalaciones deportivas para 130 personas. En la Bundesschule permanece el sentido de comunidad indisoluble de aprendices y maestros, pero esta vez con un régimen de internado mucho más acentuado. Esta escuela de formación continua, también heredera de la reforma educativa alemana, concede el mismo protagonismo a todos los edificios, incluidos los residenciales vinculados al internado y en especial a los corredores que conectan todo el conjunto y que se revelan como interesantes espacios de relación a reivindicar. En cambio en la Bauhaus de Ziebigk-Dessau, las viviendas de profesores están agrupadas pero separadas del edificio docente, localizadas en un barrio cercano, inmersas en la población. En el edificio docente la residencia se limita a la torre de viviendas-estudio, muy contenida.

3. GARCíA, R.: “Jan Duiker. 1890-1935: Esbozo de una vida truncada”.Cuaderno de Notas, 2004, n. 10, p. 75 y MILELLI, G.: Zonnestraal, il Sanatorio di Hilversum. Bari : Dedalo Libri, 1978.

4. Evitando reproducir imágenes ya publicadas, para observar la oficina del director de Weimar (1924) recomendamos DROSTE, M.: Bauhaus. Köln, Taschen, 2006. pp.42, 43. 


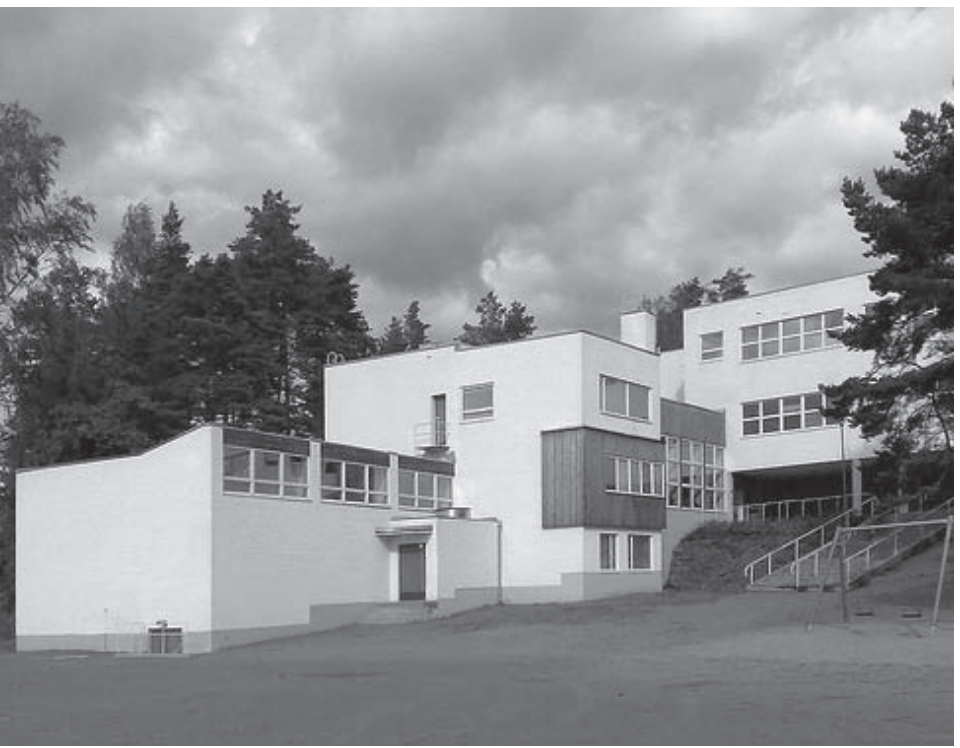

4. Escuela primaria en Inkeroinen, Alvar y Aino Aalto (1936-38). La planta en L es un recurso tipológico muy común en la arquitectura de tradición nórdica; tiene relación con la adaptación geográfica y la generación de recintos y espacios exteriores protegidos frente a los vientos dominantes. Este ejemplo es ilustrativo de una forma de articular la arquitectura con el relieve natural del suelo, que también se observa en la Bundesschule de Bernau y en la Hogschule für Gestaltum de UIm.
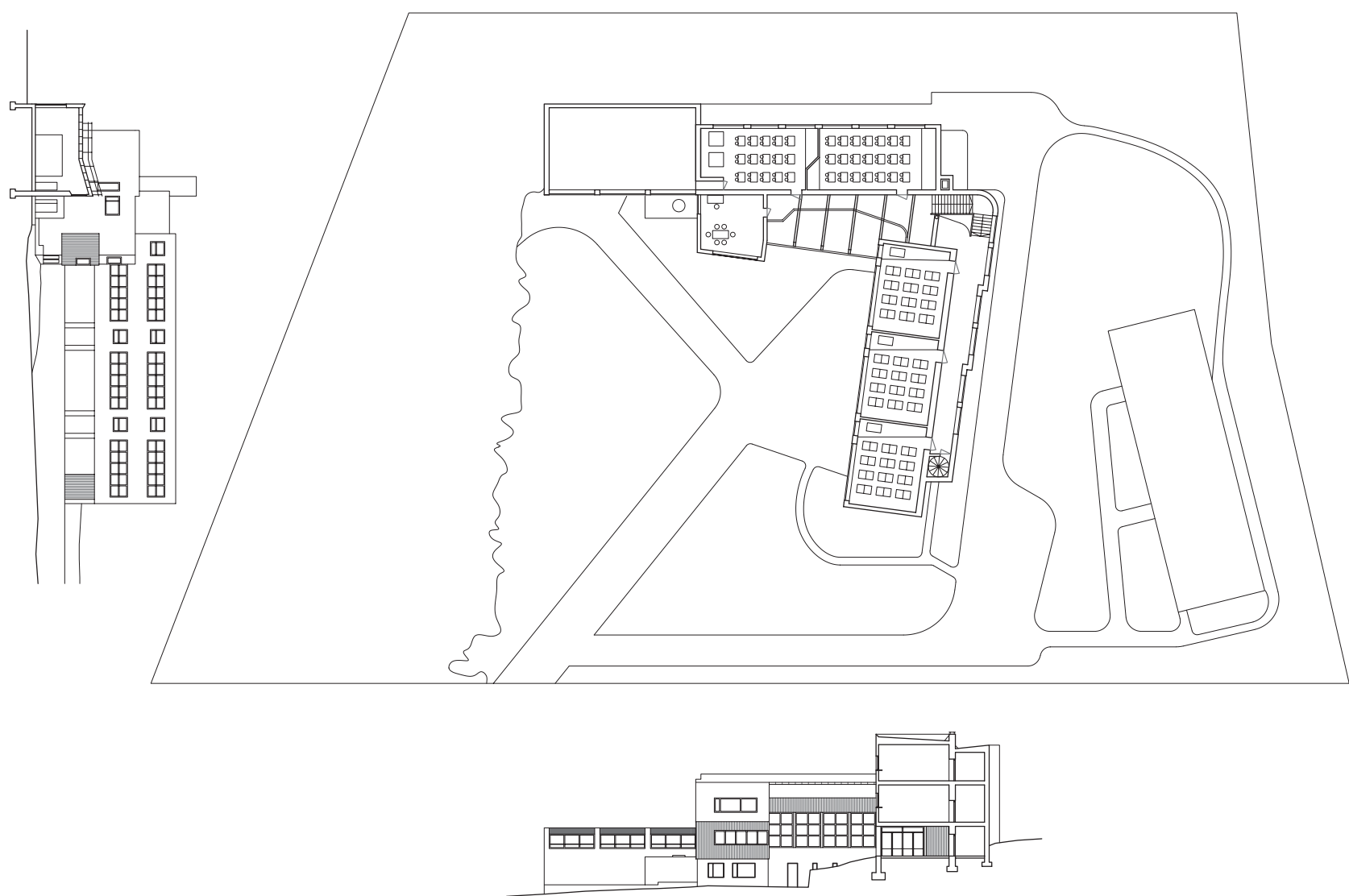
Esta presencia reducida de la residencia en el edificio escolar permite diversas interpretaciones: podría tratarse de ensayar dos modos diversos de solucionar la residencia, integrada o separada del lugar de trabajo; podría deberse también a una voluntad de explicitar la limitación de plazas de internos en una institución de élite, o simplemente de incorporar la función residencial de forma mínima, ante la imposibilidad de un programa de mayor tamaño. Pero la divergencia en la forma de incorporar la residencia en el edificio escolar se debe principalmente a la voluntad de integrarse en la ciudad o por el contrario, permanecer aislado.

La intención de implantarse en un lugar distante, como organismo autónomo a la espera de ser finalmente absorbido y asimilado por la ciudad, que puede leerse en la experiencia de la Bauhaus en Ziebigk-Dessau, resulta también contrariada por el proyecto de Meyer, que parece evidenciar el deseo de mantenerse como objeto independiente, aislado y distante tanto de Berlín como del núcleo de Bernau. El edificio de Meyer genera y a la vez se apropia de su espacio inmediato, para el que reivindica un carácter natural en el tratamiento de los jardines y los espacios deportivos mediante la adaptación del edificio a la topografía original del terreno ${ }^{5}$.

En aquellos primeros años de la modernidad, las ideas higienistas habían calado en la sociedad y junto a los sanatorios y establecimientos para el control sanitario de la población, proliferaron muchas escuelas jardín; además de la modélica y conocidísima escuela al aire libre de Ámsterdam construida con proyecto del arquitecto Jan Duiker (1927-30), se pueden citar multitud de ejemplos que adoptaron la lógica funcionalista como pauta y profundizaron en la materialización de la arquitectura de aire libre en todas las latitudes. Este es un tema ya muy estudiado y publicado que no veo oportuno reproducir aquí, aunque considero necesario mencionarlo por ser una referencia clave para la comprensión del contexto. La idea de ciudad jardín se infunde a una gran parte de la arquitectura pública producida en los años intermedios a las dos guerras mundiales, periodo en el que la entonces novísima tecnología de la construcción en hormigón armado también se propagó con asombrosa velocidad en el ámbito internacional. La obra de Sir Owen Williams es un ejemplo de maestría en el dominio de la tecnología del hormigón, demostrando cómo desde la experimentación y la práctica profesional de la ingeniería y la arquitectura, se pueden producir importantes avances ${ }^{7}$. Todas las obras de Owen Williams interesan, pero hay una que afronta un reto especial como es la adaptación de los alardes tecnológicos de la arquitectura industrial, a la escala mucho menor del edificio público de ámbito local: el Pioneer Health Centre en Peckham; un ejemplo idóneo también para apreciar cómo los nuevos programas emergentes para equipamientos asistenciales eran previamente probados mediante instalaciones provisionales en edificios adaptados, para finalmente promover edificios propios, ideados a medida de esos nuevos usos. Antes de definir un programa funcional definitivo, ensayaban suficientemente las necesidades de la nueva institución, garantizando un edificio ajustado a las necesidades reales de los usuarios ${ }^{8}$. Algo similar a lo sucedido con la Bauhaus, que primero se ensayó como institución en el edificio de Weimar y posteriormente construyó su nueva sede en Ziebigk, junto a Dessau.

Consecutivamente a la experiencia de la Bauhaus, la obra realizada por Alvar Aalto evolucionó desde el clasicismo nórdico a la traslación casi literal de la experiencia funcionalista europea en obras como el Sanatorio de Paimio (1929-32), actitud inmediatamente revisada desde una interpretación personal con evidentes rasgos expresionistas, como se puede apreciar en la Escuela Primaria de Inkeroinen (figura 4), en la que se observa una liberación del dogmatismo formal del Movimiento Moderno ${ }^{9}$.

5. BENHE, A. La escuela de la Asociación General de Obreros Alemanes en Bernau. Arquitectura, № 112, Madrid, 1928. pp. 254 a 263. /AÑÓN ABAJAS, R. Ma .: La arquitectura de las escuelas primarias municipales de Sevilla. Col. Kora, 15. Sevilla. Universidad de Sevilla y Junta de Andalucía, 2005. pp. 66, 67. / DROSTE, M.: Bauhaus. Köln, Taschen, 2006. pp.74 y sig.

6. Hay multitud de estudios sobre el tema. Algunas fuentes para ampliar bibliografía son AÑóN ABAJAS, R. Ma.: La arquitectura de las escuelas primarias municipales de Sevilla. Col. Kora, 15. Sevilla. Universidad de Sevilla y Junta de Andalucía, 2005 y CHÂTELET, A.M. LE COEUR, M. L'architecture scolaire. Essai d historiographie nternationale.- Paris, Histoire de l'education, 2004.

7. En el año 1926, Sir Owen Williams publicará su artículo sobre "la sinceridad estructural", contestando a los arquitectos que pretenden ocultar sus sofisticados diseños estructurales, detrás de banales revestimientos a modo de máscara estilística. YEOMAN, D. Owen Wiliams. London: Thomas Telford, 2001.

8. AÑóN ABAJAS, R.M. Una obra de Sir Owen Williams: El Pioneer Health Centre en Peckham Londres, 1933-35. En TRILLO DE LEYVA, M. (dir.) RAMOS CARRANZA, A. (coord.). Construyendo Londres, dibujando Europa. Sevilla, FIDAS/COAS, 2006. pp. 39 a 55.

9. La escuela primaria de Inkeroinen se proyecta y realiza simultáneamente a la conocida Villa Mairea en Noormarkku, años 1938 a 1939. Salvando las diferencias de los presupuestos disponibles para la realización de la villa noble y la escuela pública, se aplican soluciones constructivas muy similares en ambas obras. 


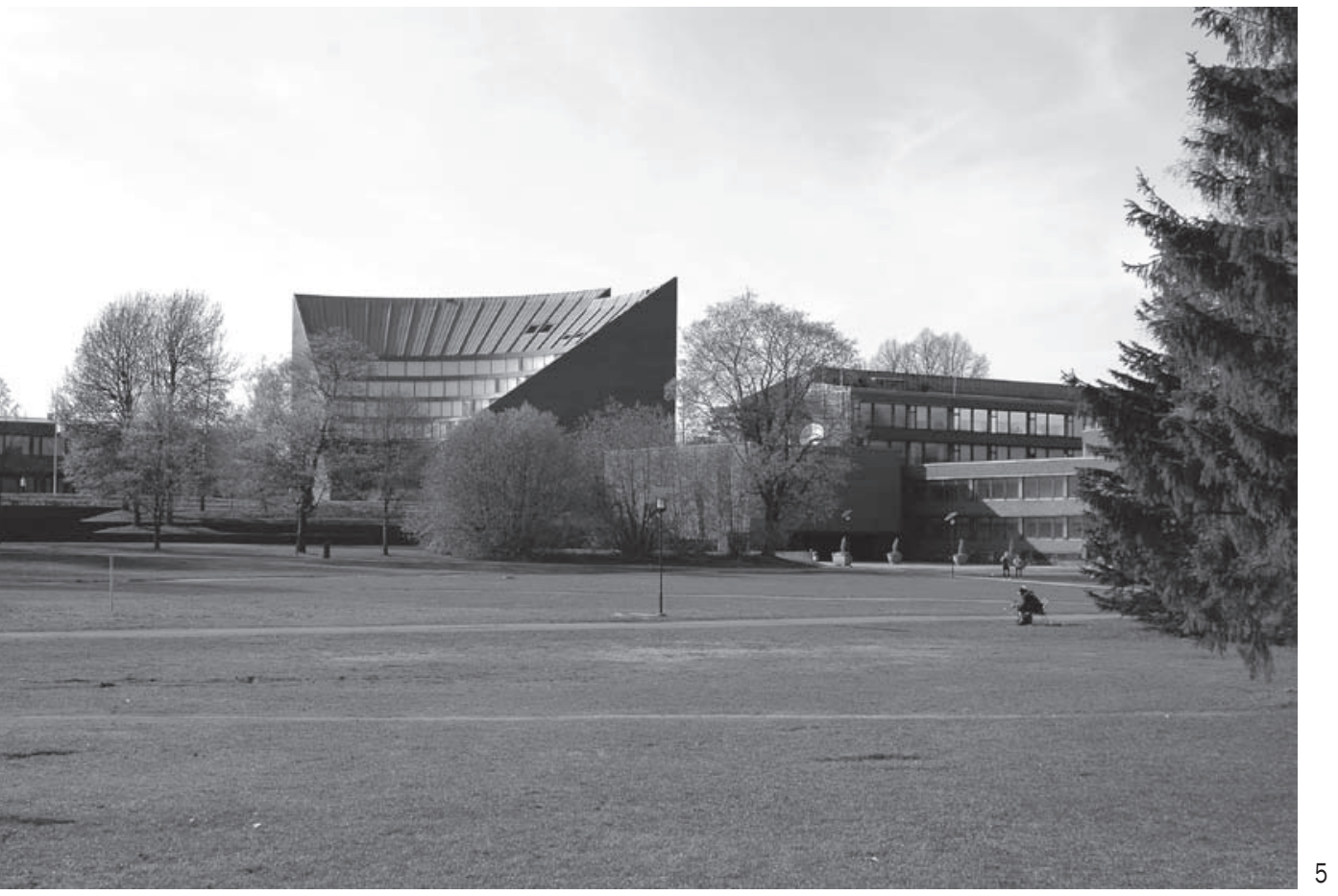

5. Helsinki University of Technology en Otaniemi, Alvar Aalto, 1949-76. Los amplios corredores de conexión entre los distintos pabellones y la presencia protagonista del aula magna, insisten en la interpretación romántica del funcionalismo que se hace desde el expresionismo. En esta obra, Aalto recurre ya a citar su propio repertorio personal. El alarde técnico en la cubierta del aula magna, sólo podría justificarse como ensayo estructural.

Mucho después, los edificios para el complejo de la Helsinki University of Technology en Otaniemi, cuya realización se extiende desde 1949 a 1976, mantienen todavía la memoria de la Bauhaus como referencia en lo esencial $^{10}$. En Otaniemi los recursos formales han evolucionado nuevamente en relación a las circunstancias tecnológicas del contexto y particulares de la experiencia propia del arquitecto Aalto, pero se puede afirmar que los fundamentos teóricos son claramente continuistas con la actitud regeneracionista y funcionalista de la Bauhaus: antención a la iluminación y ventilación natural, relación con la naturaleza y aperturas hacia el espacio abierto circundante, adaptación e interacción con el relieve topográfico, etc. En cambio pierde valores como la justedad del tamaño y la moderación en el empleo de materiales. La escuela de arquitectura en Otaniemi, esponsorizada por industrias finlandesas relacionadas con la construcción, también fue y sigue siendo una escuela dirigida a un grupo minoritario y muy selecto de estudiantes, es decir, una escuela de élite en cambio sus instalaciones aún hoy pueden calificarse de monumentales (figura 5).

Son ejemplos suficientes para mostrar la repercusión de la Bauhaus, no sólo en la recurrencia del lenguaje formal o de la imagen, sino también en la organización espacial y la anatomía de estos edificios. Observemos la equivalencia en la cualidad de los materiales, de los estucos, los colores, los diseños de herrajes, barandillas y pasamanos de las escaleras, la ligereza de las carpinterías de los enormes paños acristalados. Pero observemos también la expresión de la estructura, las vigas y voladizos que aparecen modulando los techos de todos estos edificios, o el interés por materializar la conexión entre cada decisión tipológica y tecnológica con la solución estructural y con la definición material última, con la imagen final. El sello común de todas estas obras es innegable: una idea de arquitectura y una actitud activa y crítica desde el proyecto arquitectónico, la única disciplina capaz de integrar toda la información que maneja el arquitecto y concretarla en una obra, dándole sentido. La posición cronológica de la escuela de Dessau entre todas las obras mencionadas, permite deducir cómo la institución apostó por constituirse construyendo un modelo de arquitectura ejemplar y extraordinariamente influyente, considerando esto como un primer paso indispensable para la formación de la inquietud de sus estudiantes por comprender y dominar las infinitas posibilidades de la arquitectura moderna.

Como ocurre con casi todas las instituciones que han hecho historia, la Bauhaus no fue una aventura personal de ningún arquitecto en particular, sino el resultado del trabajo de un colectivo comprometido en un proyecto 
común, necesario y oportuno en su momento, que culminaba un proceso progresivo propio del sistema educativo alemán. Con origen en la Escuela de Weimar, comenzó una primera adaptación de la escuela de oficios artísticos para abarcar nuevas especialidades en las artes modernas, incorporando progresivamente novedades como la fotografía, el cine, la escenografía, etc. Cuando se concibió el proyecto de Dessau, los objetivos de la institución y la organización funcional del edificio ya estaban más que probados. Un colectivo limitado, una ratio de estudiantes por profesor muy baja, un aprendizaje mediante sistema de taller práctico, similar al seguido por los oficios artesanos en el medioevo. El espacio ideado para contener los talleres se concibe isótropo y polivalente para admitir cualquier materia y experimento, acorde al espíritu dinámico de la institución.

El edificio de Dessau supuso una apuesta radical por verificar la idea del funcionalismo y medir el equilibrio entre novedad tecnológica, producción industrializada y control artesanal de la obra de arte. El resultado fue tan acertado que por sí mismo consiguió educar, motivar, consolidar y publicitar una institución prometedora, que fue capaz de convencer de la utilidad del arquitecto a la sociedad de su época. A pesar de los directores (Gropius, Meyer, Mies) que sucesivamente ensayaron nuevas orientaciones en los programas ofertados, la Bauhaus no dejó de tener un principio común y una idea clara sobre el valor de la arquitectura y su papel activo en el progreso social.

\section{LA HOLTSCHULE FÜR GESTALTUNG EN ULM}

La experiencia de la Holtschule für Gestaltung en UIm, fundada y construida por Max Bill a mediados del siglo XX es menos conocida, aunque ya se encuentran algunas publicaciones que describen el edificio y ofrecen algunos datos de su historia. Se trata aquí de revisar y completar esa información con una interpretación que pone en relación su existencia con sus antecedentes, presentando esta obra como la consecuencia de una larga sucesión de hechos y como una profunda síntesis que se concreta en esta institución y su arquitectura.

La iniciativa fue animada por un grupo de intelectuales que emprendieron el reto de revivir el espíritu de la Bauhaus en Alemania, que había sido truncado por la Segunda Guerra Mundial; un argumento abiertamente sentimental que sirvió para lograr el apoyo de suficientes patrocinadores.

El proyecto para el edificio de la HfG fue iniciado por Max Bill en el año 1950, la construcción comenzó en 1953 y la escuela empezó a funcionar en 1955, aunque el proyecto no se encontraba ejecutado totalmente, a falta de algunas unidades de habitación tanto para profesores como para asistentes y estudiantes. La inauguración oficial se celebró en 1957, con la presencia de Gropius ${ }^{11}$.

La construcción como instrumento práctico de educación Al principio el experimento de la HfG siguió los criterios pedagógicos que Max Bill expuso en el IX congreso de los CIAM en Aix-en Provence en 1953. Aquél mismo año un grupo de estudiantes inició el primer curso de enseñanzas fundamentales, mientras el edificio de la HfG iba construyéndose en paralelo. La construcción de la escuela se incorporó como instrumento práctico de educación.

Max Bill defendía que el fin pedagógico que se debe proponer una escuela de arquitectos y urbanistas es la educación de personalidades independientes, dignas de confianza, dotadas de cualidad crítica y de sentido de la responsabilidad. Fines que debían ser conseguidos mediante el desarrollo de su facultad creativa, para hacerlos capaces de plasmar los ambientes en donde se desenvuelve la vida y responder a las complejas exigencias de los hombres y la sociedad de la edad de la máquina.

10. En Paimio la imagen de las escaleras prueba la literalidad en la traslación del lenguaje de Dessau y verifica la búsqueda del elemento arquitectónico reproducible. Años después en Villa Mairea y en la Escuela de Inkeroinen ya ensaya como fusionar la teoría de la modernidad y la tradición del espacio doméstico arraigado en la cultura local finlandesa. En ambos casos Aalto adopta los recursos locales como tecnología de construcción, aunque con un nivel de elaboración muy diferente en correspondencia los presupuestos manejados en la villa burguesa y en la escuela pública.

11. STABER, M.: "La scuola di Ulm”. Casabella continuità, 1962 Jan., n. 259, p. 12. / GIMMI, K. GÜNTERT, G.: "Hochschule für Gestaltum, Ulm”. En GIMMI, K. y otros: "Max Bill Arquitecto". 2G, Revista internacional de arquitectura, 2004, n² 29-30.- pp. 108-135. 
Las competencias educativas debían ser ejercitadas por profesores dotados de grandes cualidades morales y artísticas, que tuvieran experiencia y ejercitasen su profesión de arquitectos. El docente debía ayudar al estudiante a desarrollar su propia personalidad y conciencia, para que llegase a ser capaz de responsabilizarse de sus propias acciones y defender así el valor de su trabajo. Para el desarrollo de este sentido de responsabilidad el programa preveía también lecciones de filosofía, sociología y ciencias políticas. En Ulm, se le dio máxima importancia a la experimentación. La sección de "edilicia" se especializó exclusivamente en prefabricados. La sección de urbanística no pudo realizarse y se excluyó del programa.

El ejercicio educativo debía desenvolverse en el marco de la vida real, lo que significaba que los objetos de estudio tenían que ser problemas reales. Como condiciones ideales para la educación de los arquitectos defendía el trabajo en talleres en los que cada profesor atendiese a grupos de quince estudiantes como máximo. El taller debía seguir el modelo de un estudio para arquitectos y proceder del mismo modo que en la vida real. Además de los estudios individuales debían llevarse a cabo trabajos en equipo. El trabajo de taller debía desarrollarse coordinadamente con las otras facultades de la escuela, y sobre esa base debía desarrollarse un trabajo colectivo sobre el modelo de una asamblea parlamentaria, porque así los estudiantes se ejercitaban en el método de la autocrítica y de la defensa de propio trabajo.

El estudio de las funciones, de la construcción y del sentido espacial debía ser el fundamento de la obra y el estudiante debía participar en la responsabilidad de su realización. Algunos estudiantes fueron emplazados como ayudantes de dirección a pie de obra. Estos arquitectos principiantes debían afrontar los problemas prácticos del construir con todas las dificultades conexas. Esta actividad dirigida por el arquitecto Friedrich Pfeil, docente de la sección de arquitectura, era muy popular entre los estudiantes y por eso se establecieron condiciones mínimas para la admisión: se pedía a los aspirantes que previamente hubieran realizado un curso de arquitectura o de ingeniería de la construcción, además de los fundamentos del diseño edilicio, la actividad práctica en un estudio de la arquitectura o de alguna profesión artesanal o técnica y demostrar también tener nociones fundamentales de estática, de construcción y de historia. Eran las enseñanzas que se impartían en el primer año y que en el curso inaugural de la HfG contaron con la colaboración de ex-docentes de la Bauhaus como Josef Albers (que era entonces director de la sección artística de la Yale University) y Walter Peterhans (entonces profesor en el Illinois Institute of Technology de Chicago).

La HfG fue construida insistiendo desde el origen de la idea en el valor de lo esencial, en la austeridad y experimentando con la modulación y la normalización de elementos producibles en serie como la ventana, para evitar desperdicios de material.

El proyecto original preveía una construcción con estructura de acero y de montaje altamente industrializado, pero entonces se trataba de un material de precio muy variable en el mercado; las limitaciones presupuestarias obligaron a optar por el hormigón armado y a una puesta en obra más económica con reducción de parte del programa. El hormigón visto, construido con encofrado de madera, tomó una expresión que se integró totalmente con las carpinterías moduladas de madera y con el paisaje rural circundante; además de los prefabricados de madera, también se experimentó con elementos prefabricados de hormigón armado, llevados incluso a la estructura portante.

La sistematización del proceso constructivo conduce a organizar todo el conjunto en base a una retícula de seis por seis metros, con cuatro pilares y dos jácenas, sobre la que descansan una estructura secundaria de paneles prefabricados de hormigón con tres metros de altura. En las fachadas, un orden secundario a tres metros ofrece el canto visto de los paneles para modular las fachadas y así todos los cerramientos se pudiesen construir con elementos seriados, atendiendo a una modulación de cuatro particiones en dirección vertical y tres en dirección horizontal, que facilitaba todas las variaciones necesarias. Se utilizaron los mismos materiales al exterior y al interior: hormigón visto, madera de pino, ladrillo visto pintado en blanco, planchas asfálticas en los pavimentos y prefabricado de terrazo en los peldaños de escaleras.

Los elementos de iluminación y el mobiliario se diseñaron y construyeron con similar intención didáctica, haciendo de la austeridad material y la simplicidad formal una motivación para experimentar los conceptos fundamentales. 


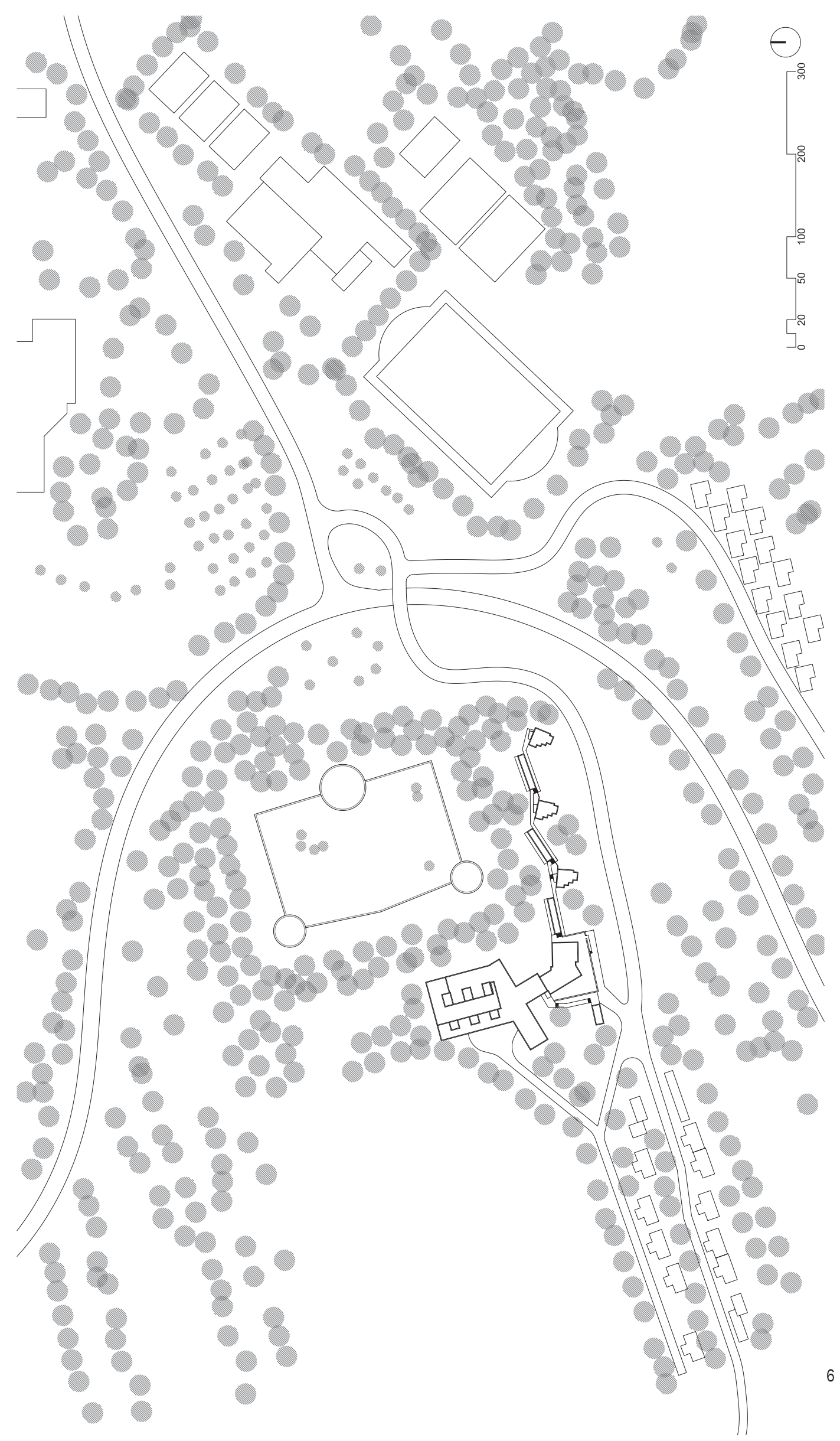




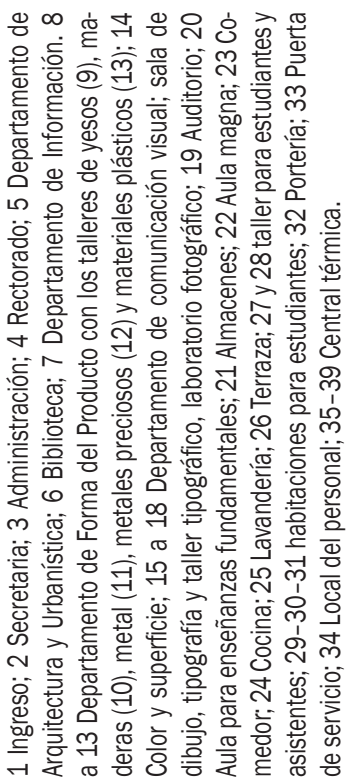

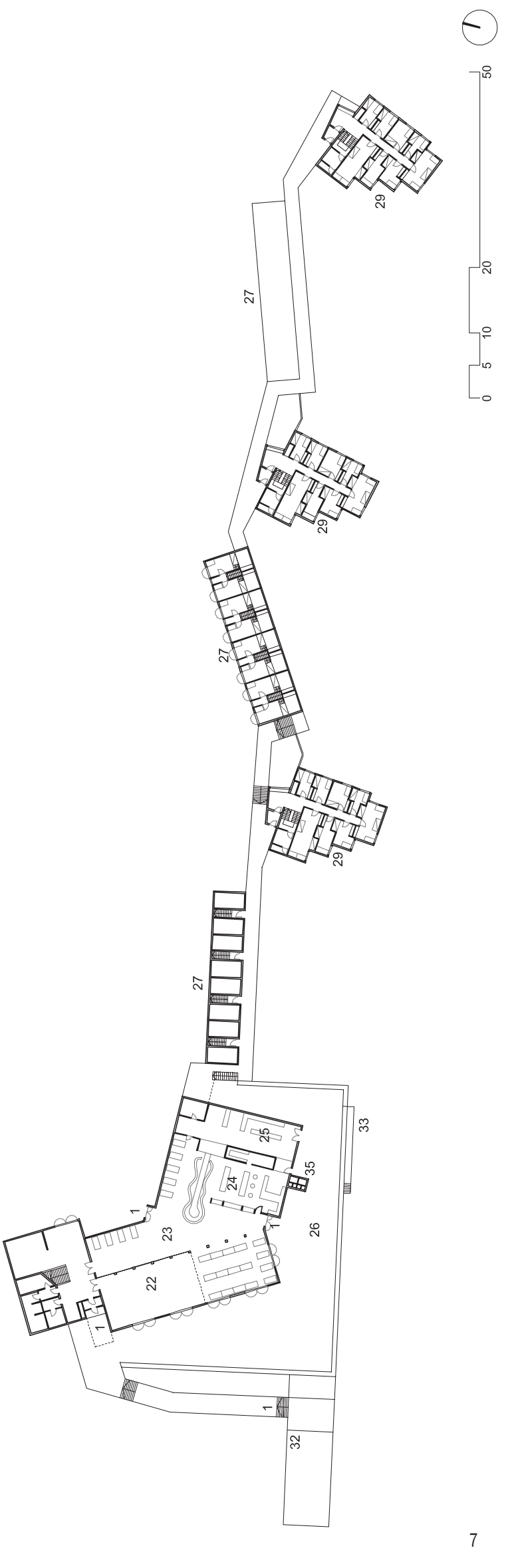


7. HfG en Ulm. Max Bill, 1953-

55. Planta general. Programa de funciones y espacios en el edificio de la escuela:

8. HfG en Ulm. Max Bill, 195355. Sección y alzado general. Las fotografías presentan varias vistas del acceso desde la fachada sur hasta la entrada principal.
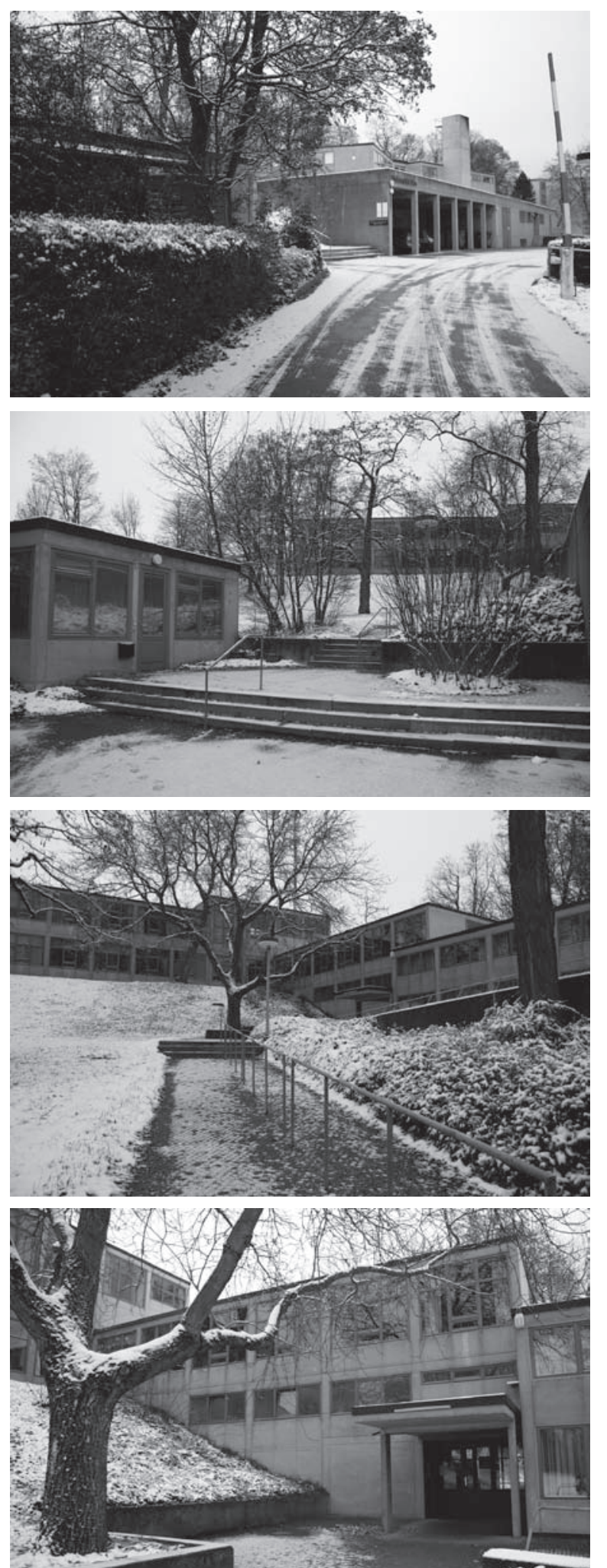

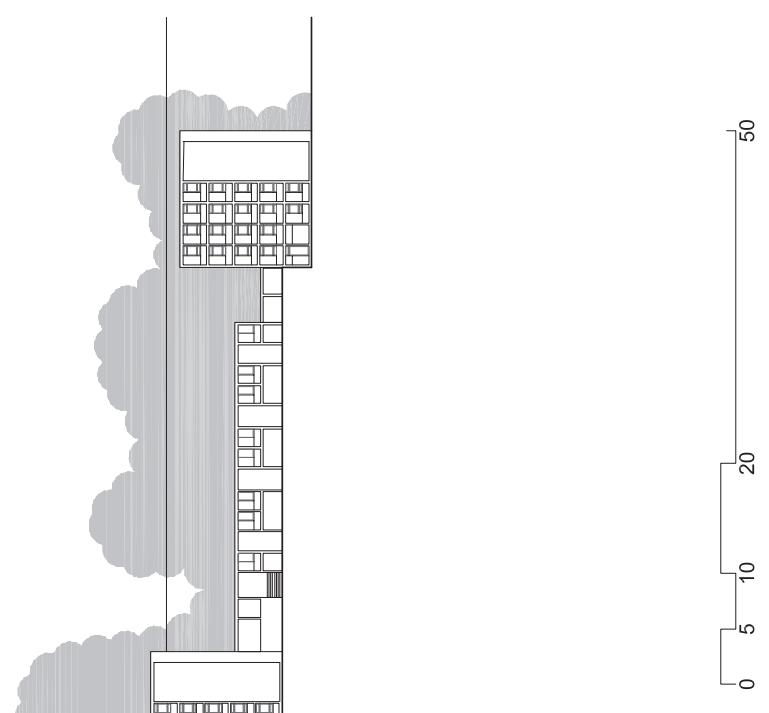


9. HfG en Ulm. Max Bill, 1953-55. Vistas del cuerpo de talleres desde las fachadas oeste, norte y este.

10. HfG en Ulm. Max Bill, 1953-55. Varias vistas de la conexión del edificio de administración y servicios con las viviendas estudio de asistentes y torres de habitaciones de estudiantes.

La posición respecto a la ciudad

Antes se ha observado como la Bauhaus y otras experiencias funcionalistas optaron por establecer diferentes relaciones con la ciudad, implicándose en condicionar su desarrollo o procurando una independencia permanente, como ocurre en este caso.

El conjunto de la HfG de Ulm se localiza al suroeste de la ciudad en la colina del Oberer Kuhberg, sitio de una defensa militar construida en el siglo XIX (figura 6), en contacto con el paisaje rural, carácter que actualmente conserva ese lugar y que acentúa la condición de retiro de este internado, en la línea de las ancestrales instituciones monacales, una valoración de la naturaleza que también manifestaron las escuelas al aire libre emplazadas en los bosques, o las residencias suburbanas del romanticismo alemán. Algunas imágenes de los espacios y recorridos exteriores de la HfG son citas casi literales de las arquitecturas que Karl Friedrich Schinkel realizó en Glienicke como el casino-embarcadero, que además de construir el paseo, acota el recinto y enmarca el paisaje ${ }^{12}$. La fragmentación de los volúmenes construidos para su adaptación a la topografía y el protagonismo del vidrio en la expresión del edificio, acusan también la componente romántica y expresionista de esta obra. El romanticismo del XIX como reacción al neoclasicismo, rescató la lógica y la racionalidad constructiva del gótico; en el siglo XX en cambio, miró a la ingeniería y las grandes obras de la arquitectura industrial. Las fotografías de la HfG de Ulm, especialmente las nocturnas, acusan esta conexión con la arquitectura industrial como referente, recordando el discurso sobre "la sinceridad estructural" que Sir Owen Williams desarrolló y aplicó en su obra construida hasta materializarlo y expresarlo con total plenitud; él también solía fotografiar sus obras de noche y con las luces encendidas, imagen que como una radiografía, revelaba el rigor estructural desprovisto de todo revestimiento.

Con independencia a que el lugar para establecer la HfG fuese buscado o hallado, la interpretación que hace la arquitectura de Max Bill es inequívoca. Apuesta por el contacto con la naturaleza y el aislamiento de la ciudad tradicional con la idea de realizar un centro de dedicación intensiva al aprendizaje y la enseñanza de la arquitectura, en base a la experimentación de novedades tecnológicas para la producción en masa, que requieren una reflexión propia. Se trata de alcanzar el ideal, una proximidad entre la vivienda y el lugar de trabajo, sin renunciar a la diferenciación clara de ambas funciones.

\section{Organización funcional de espacios}

Partiendo de considerar la etapa de aprendizaje y también la actividad del profesorado dedicado a la enseñanza y la investigación para el perfeccionamiento de la profesión, el conjunto de la escuela de Ulm se diseñó como un centro de alto rendimiento. Los talleres y las aulas disponen de una óptima relación con los comedores, los espacios de foro, para facilitar descansos rentables para el trabajo productivo. También se pensó en facilitar viviendas a profesores y estudiantes, reduciendo los desplazamientos entre el trabajo y la residencia.

Antes de seguir, conviene examinar la documentación gráfica que se aporta para describir el conjunto de la HfG de Ulm: las plantas (figura 7), alzados, secciones y las fotografías. Se han realizado expresamente para este artículo, revisando toda la documentación anteriormente publicada por la bibliografía consultada, realizando una síntesis y aportando nuevas imágenes insólitas ${ }^{13}$.

Observando las plantas se comprende que la disposición de locales se organiza atendiendo a dos circulaciones diferentes, de una parte la de los estudiantes internos, de otra la de los estudiantes externos y profesores. Los visitantes acceden a través de la portería y atravesando el jardín llegan a la puerta principal del portal que vincula los locales comunes de ocio y los espacios de trabajo (figura 8).

Los edificios de habitaciones para alojar a los estudiantes y las hileras de viviendas-estudio para los asistentes, se comunican por un corredor que conduce directamente al comedor y al aula magna, que en ambos casos se relacionan con una amplia terraza al sur, constituyendo un lugar ideal para la vida comunitaria y que conecta con la escuela mediante el portal de entrada de los externos; desde este portal una escalera conduce al pasillo que

12. RAMOS CARRANZA, A.: "Utopías de arquitectura: paisajes para otra ciudad”.- En RAMOS CARRANZA, A. AÑÓN ABAJAS, R.M.: Arquitectura y construcción: el paisaje como Argumento. Col. Ensayos para un nuevo hábitat urbano, n1.- Sevilla, UNIA, 2009.- pp.29-48.

13. La documentación gráfica más completa se encuentra en GIMMI, K. GÜNTERT, G.: "Hochschule für Gestaltum, Ulm”. En GIMMI, K. y otros: Max Bill Arquitecto. 2G, Revista internacional de arquitectura, 2004, n² 29-30.- pp. 108-135. 

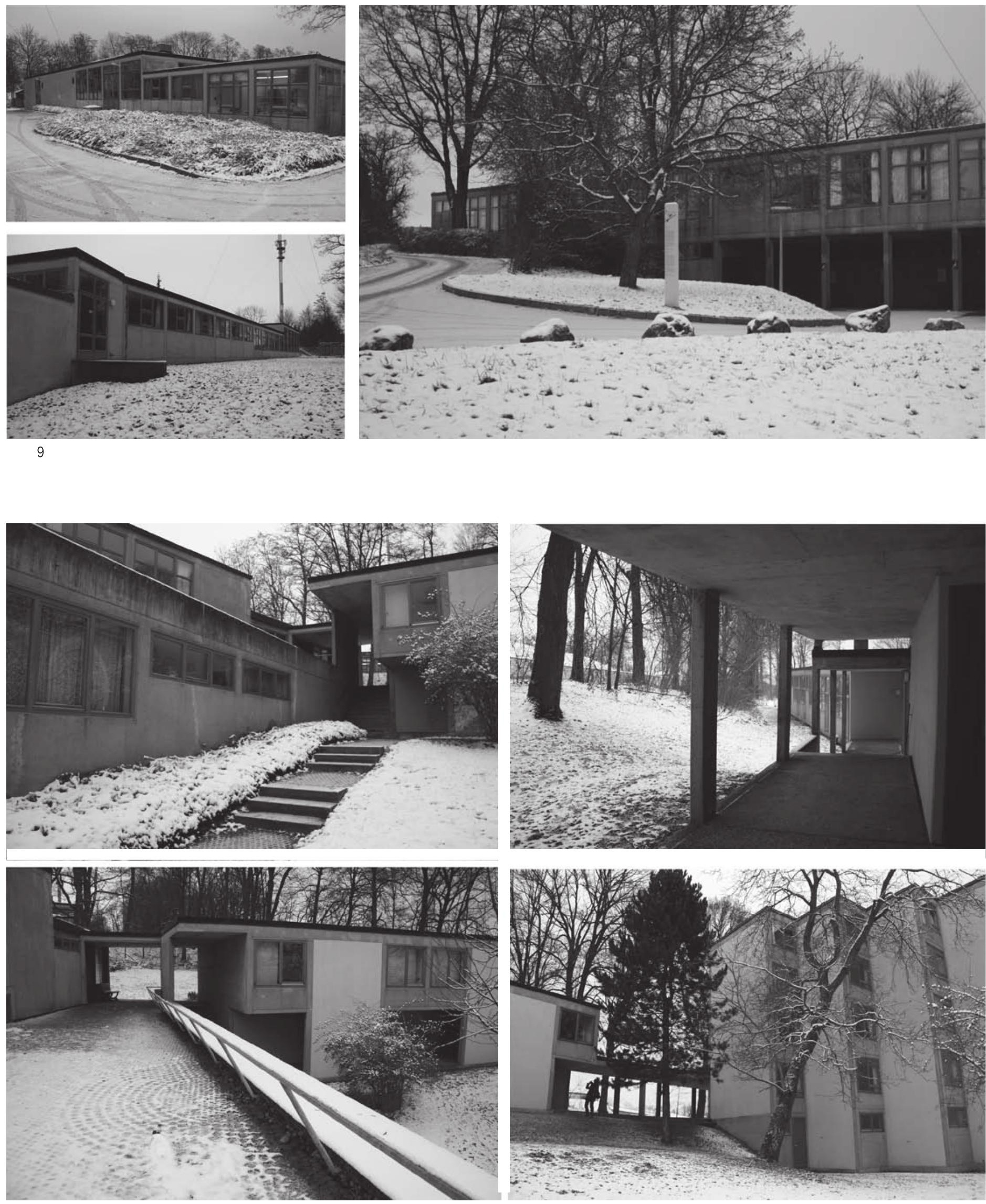
atraviesa las zonas de administración y biblioteca para llegar a un gran espacio de forma singular y que comunica con el exterior por portales secundarios en sus extremos este y oeste, de este distribuidor parten los recorridos a los distintos espacios de trabajo. Al oeste, un ala de dos plantas para el Departamento de "Arquitectura y Urbanística" con un gran auditorio destinado a la enseñanza fundamental en el piso superior, directamente relacionado con los talleres. En el ala opuesta encontramos el Departamento de "Información" y en la nave intermedia, relacionada con los dos departamentos anteriormente mencionadas, se encuentra el Departamento de "Forma del Producto y Comunicación Visual". Las aulas de dibujo se disponen a lo largo de los patios interiores, disfrutando de una atmósfera tranquila. Los talleres para la elaboración de metales, madera y yeso, tienen acceso directo desde el exterior por la calle secundaria en su fachada norte (figura 9). Los estudiantes pueden frecuentar los diversos locales sin necesidad de salir al exterior.

Las habitaciones para asistentes y estudiantes (figura 10) son en ambos casos muy compactas y austeras aunque totalmente equipadas. Todos los elementos muebles están determinados a un sitio preciso, totalmente integrados y participando de la organización tipológica del edificio. La división funcional en las viviendas con estudio se hace mediante el uso de semiplantas y escaleras. Las agrupaciones de habitaciones de asistentes y estudiantes configuran una línea fragmentada, que construye un espacio de relación a la vez que ámbitos con cierta independencia. Conjuntamente con la ladera, delimitan un recinto abierto pero de cierta intimidad, que se habita como un jardín privado (figura 11).

Las viviendas de los docentes tienen un lugar propio constituyendo un grupo autónomo pero cercano, situado al sur-oeste, desde allí un sendero conduce a la entrada principal de la escuela (figura 12). Para los profesores se disponen unidades de dos a cuatro dormitorios, con o sin estudio, pero adaptando un tipo básico que se organiza en semiplantas con acceso desde un nivel intermedio en el que se desarrolla un completo programa, con entrada, recibidor, trastero y cuarto W.C., la cocina, el comedor interior y otro al aire libre. Además en ese mismo nivel, relacionado con el recibidor, se encuentran los estudios y las cocheras. A partir del vestíbulo, sendos tramos de escalera conducen al nivel inferior donde se dispone el estar de día en relación con el jardín, o al nivel superior ocupado por los dormitorios y la sala de baño ${ }^{14}$.

\section{La adulteración del ideario y el declive de la HfG}

La HfG se realizó en Ulm y las revistas de la época dieron testimonio de la importancia que tuvo aquel experimento. En cambio, un acercamiento básico a las monografías sobre Max Bill permite comprobar que ninguna dedica mucho a este episodio de su extensa producción; cuestión que sorprende. ¿A qué puede deberse este olvido?

Después de pasados tantos años desde de los experimentos de la Bauhaus, en torno a la HfG de Ulm aún se defendía la necesidad de una escuela superior de diseño y permanecía abierto el debate sobre la estructura que debería tener un centro de ese tipo y las disciplinas que debían ser objeto de enseñanza. Las instituciones que habían optado por el modelo de escuela de élite, se habían erigido rápidamente en referentes y sus resultados habían sido muy divulgados; el conocimiento superficial de aquellas experiencias, derivó en doctrinas simplificadas que concluyeron en aplicaciones deficientes, lo que propició argumentos a los sectores contrarios a la Bauhaus para calificar sus teorías de envejecidas y reaccionarias; pronto

14. Los planos de las viviendas pueden consultarse en STABER, M.: "La scuola di UIm”. En Casabella continuità, 1962 Jan., n. 259.- pp. 2-27.

15. Los años de 1953 hasta 1956, fueron fuertemente influenciados por Max Bill, el primer rector vio la HfG como una continuación de la Bauhaus, como se declaró oficialmente en un folleto en 1952. Sin embargo pocos años más tarde, en 1956, la escuela vivió sus primeras polémicas sobre los métodos de enseñanza y el currículo. Los profesores más jóvenes exigieron un modelo de enseñanza independiente, arraigado en la ciencia y la teoría, que entraría en conflicto con la idea propagada por los "seguidores de la Bauhaus". Tomás Maldonado durante su discurso programático en la Expo 58 en Bruselas, defendió que el diseñador debía ser un socio igualitario en el proceso de decisión del diseño industrial en lugar de un artista superior. Descontento con el Modelo de Ulm y la Junta de Gobernadores, una forma de liderazgo colectivo, Max Bill renunció al cargo de rector y abandonó la HfG en 1957. <http://www.hfg-archiv.ulm.de/ english/the_hfg_ulm/history_5.html : "The Ulm model” >

16. Salvo el artículo de Staber en Casabella Continuitá de 1962, no hay publicaciones eficaces sobre el edificio hasta la monografía dirigida por Gimmi y editada por $2 \mathrm{G}$ en 2004 . 


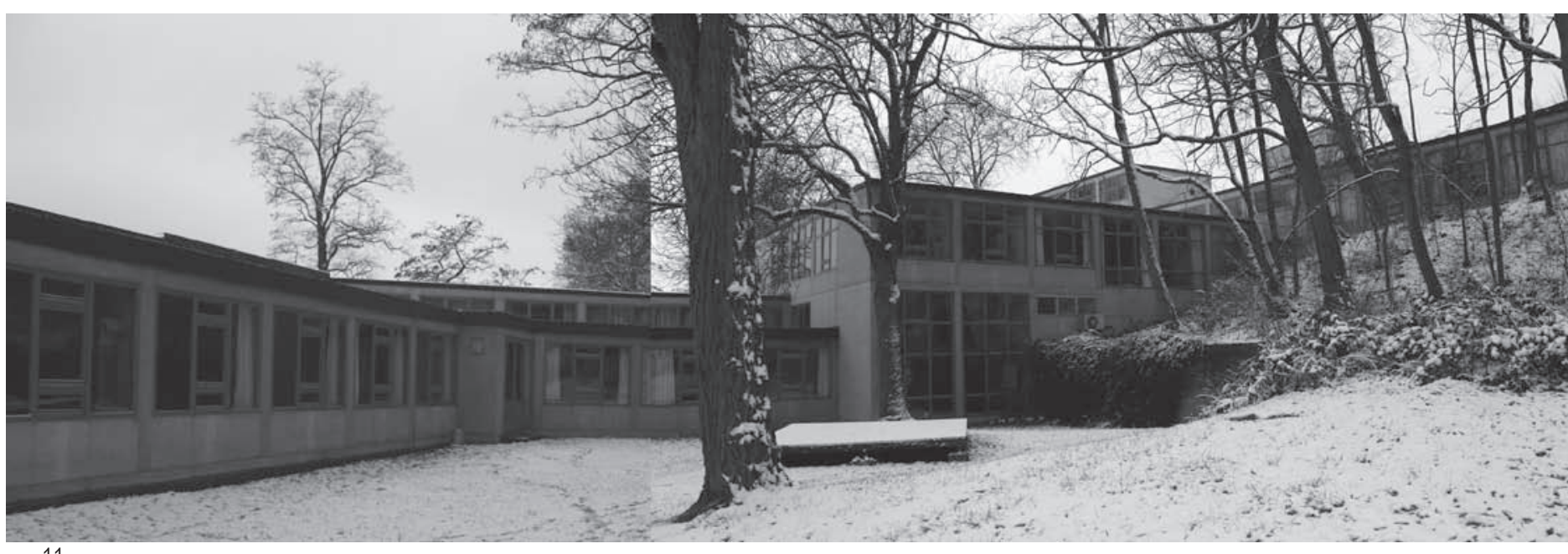

11
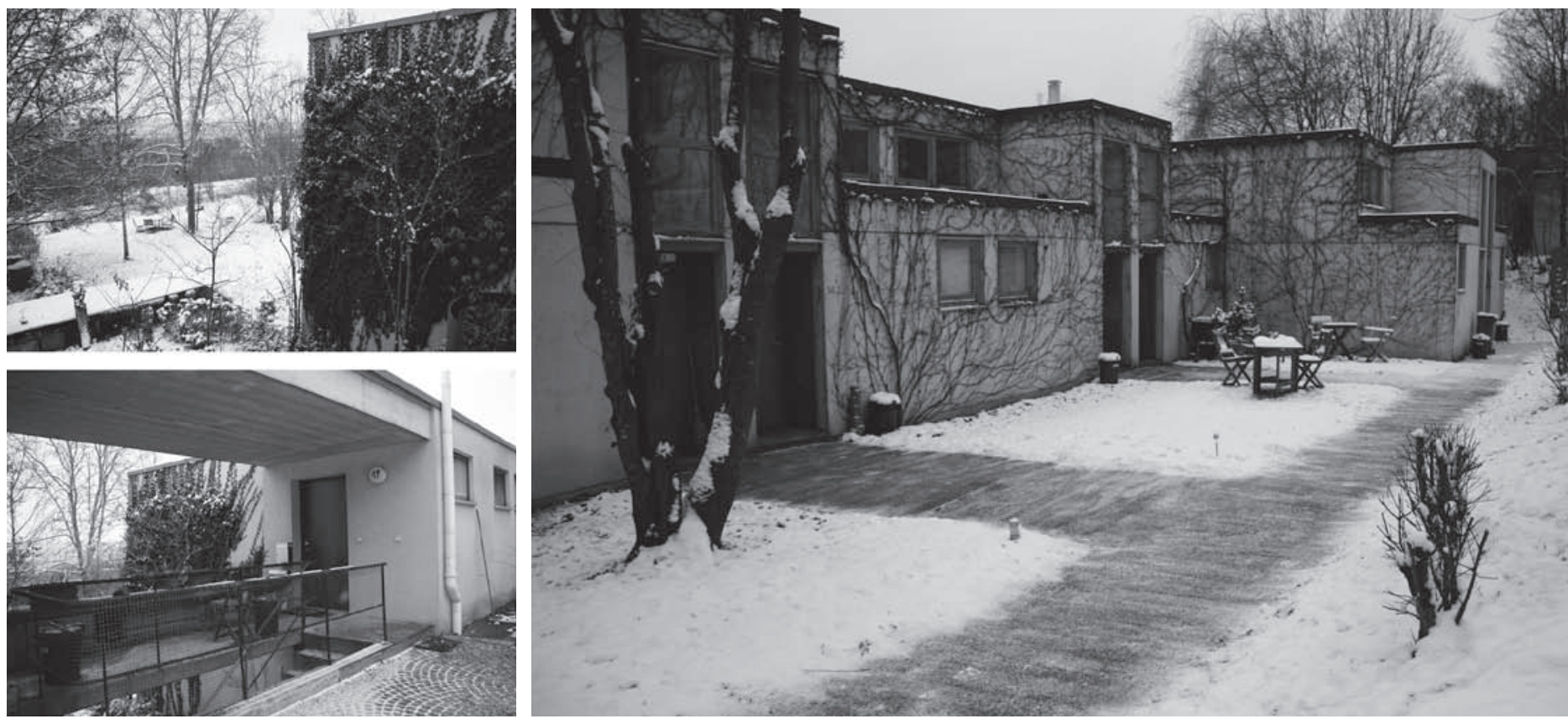

12

la polémica se instaló en la HfG llegando a pesar más las ideas radicales defendidas por Maldonado y como consecuencia, Max Bill abandonó la institución ${ }^{15}$.

La revista Casabella publicó en el año 1962 una completa documentación del proyecto que hasta entonces sólo había sido publicado parcialmente ${ }^{16}$. Declaraban tres motivos para ello: en primer lugar la $\mathrm{HfG}$ era reconocida como el ejemplo más considerable y también el más típico de la concepción arquitectónica del construir funcional representado por Max Bill. En segundo lugar entendían que los edificios escolares constituían un tema principal de la arquitectura. Finalmente, se reivindicaba la necesidad de terminar el edificio según el proyecto original de Max Bill y se denunciaban la construcción de un grupo de casas para maestros no previsto en el proyecto original y las reformas que se estaban produciendo en el interior del edificio, transformando los espacios en sentido contrario a la voluntad del autor.
Mientras Margit Staber defendía desde Casabella la arquitectura del edificio y argumentaba que lo que había cambiado eran el programa y la doctrina de la escuela. Los detractores del edificio criticaban que el edificio estaba organizado según criterios erróneos y aludían a una excesiva especialización funcional que había quedado obsoleta con el cambio de programa. El argumento no parece muy consistente si se considera que el espacio docente de la escuela es bastante isótropo, multifuncional y continuo, porque produce múltiples relaciones siguiendo un esquema matricial y tridimensional. Hoy habría aún más argumentos para la crítica fácil como el inconveniente de las muchas escaleras entre los diversos niveles en que se organiza la escuela, o la carencia de instalaciones sofisticadas como las que actualmente demandamos, porque la sociedad y en paralelo la arquitectura han asumido nuevos compromisos como la accesibilidad y la 


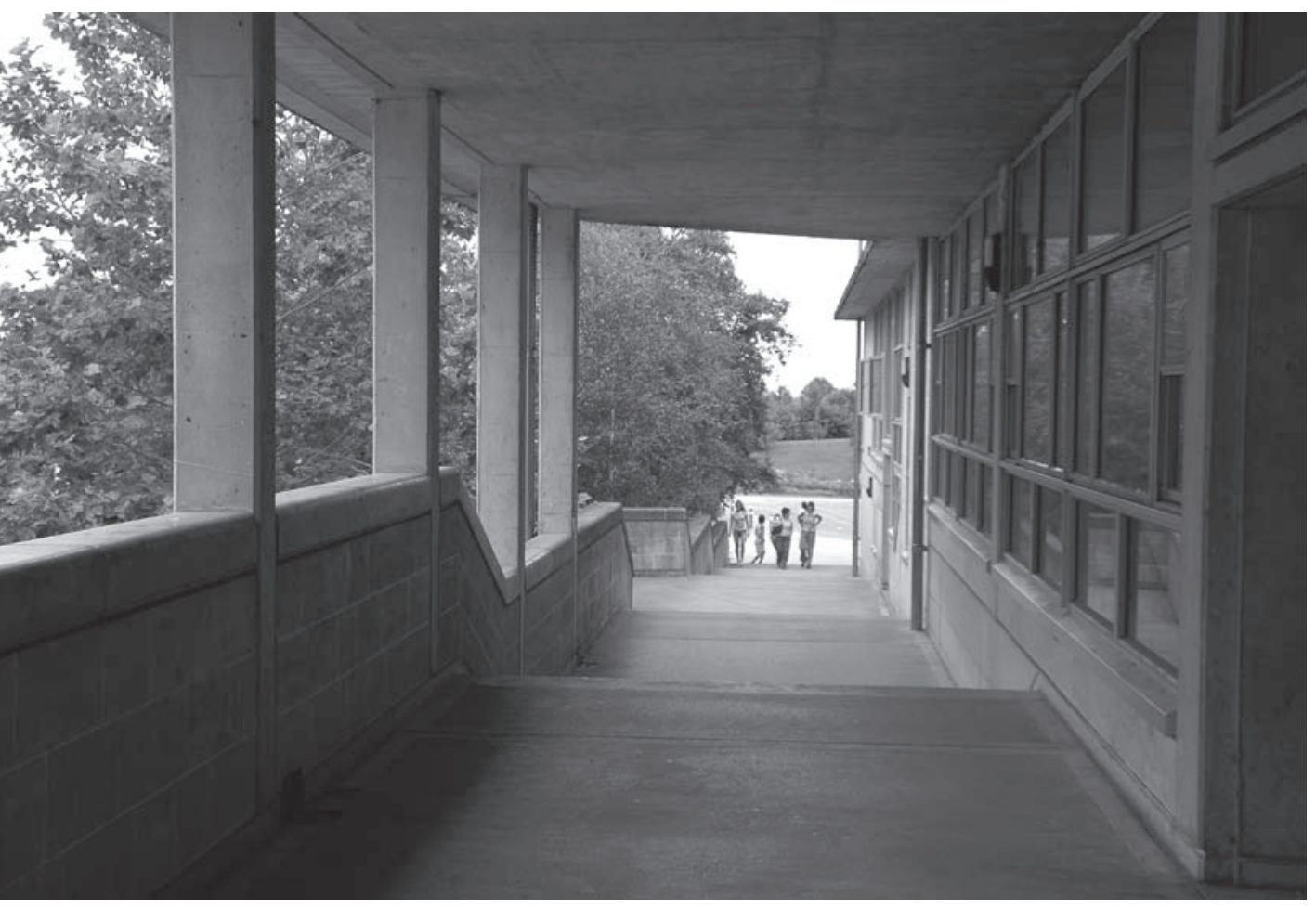

13. Escuela de Arquitectura e Ingeniería Civil de la Universidad de Bath. Peter Smithson, 1988. Vista del corredor exterior que conecta los distintos accesos al edificio.

integración de discapacitados, de la sostenibilidad y la ecoeficiencia. Estas demandas ahora ineludibles con las que todos estamos tan sensibilizados no eran tales hace cuatro décadas y muchas construcciones producidas entonces tienen hoy verdaderas dificultades para adaptarse dando respuestas a estas nuevas exigencias. No ocurre así en el caso de la HfG, que como puede apreciarse en los reportajes fotográficos recientes se conserva en muy buen estado, lo que indica la gran flexibilidad de esta arquitectura, es decir su alto índice de tolerancia a la superposición de cualquier programa y exigencia, demostrando cuánto artificiales eran las críticas que se le hicieron en los años sesenta. Al fin y al cabo se trata de una agrupación muy articulada de volúmenes muy simples, de estructura muy elemental. Sin duda el problema funcional de las escaleras no era lo que preocupaba en 1962, más bien debió ser la dificultad que deriva de la progresiva especialización del conocimiento y en consecuencia, la demanda de una fragmentación de la unidad del edificio en nuevas áreas cada vez más independientes; una división espacial inviable en un edificio ideado como contenedor de una actividad única e integradora como es el proyecto de arquitectura.

Al principio de este texto se han repasado algunos antecedentes que analizan la genealogía de esta obra y su directa relación con la arquitectura de Hannes Meyer. Igualmente podrían apreciase sus paralelismos con otras obras coetáneas como la de Scharoun y la de Aalto; también podrían establecerse relaciones con obras consecutivas que siguieron indagando en la línea de trabajo marcada por Max Bill, como puede ser el caso de las obras de Stirling y de los Smithson (figura 13). La apreciación de esta obra de Max Bill en relación al estado del debate arquitectónico en los años 50 nos permite entender mejor este complejo proyecto elemental y lo que supone su aportación al anticiparse a la arquitectura de los 70, además de aproximarnos a la personalidad del autor.

Aunque glosada ahora, después de transcurridos tantos años, la experiencia de la HfG pueda parecer una historia idílica, acabó mal como la primera Bauhaus; su brillo duró poco y la diversidad de intereses pronto derivó en conflicto, aunque como legado dejó un edificio excelente que ha servido bien y aún sirve a otras comunidades científicas. El edificio de la HfG que se construyó expresamente para un programa pedagógico muy reflexionado destilado de la Bauhaus, ha sobrevivido y sigue en servicio, ocupado ahora por la Clínica Universitaria para medicina psicosomática y psicoterapia ${ }^{17}$. Seguramente su flexible organización funcional, su situación en el borde exterior de la ciudad y su esquema de organismo autónomo e independiente, características que han permanecido estables e invariables, han contribuido a asignarle su actual uso. 


\section{Bibliografía}

AA.V.: Max Bill.- DPA 17, Mayo 2001.- Barcelona: Ediciones UPC, 2001.

ABEL, Chris: “Ulm HFG Department of Building”. Architectural Association journal, 1966 Sept.-Oct., v. 82.- pp. 88-90.

AÑÓN ABAJAS, Rosa María: La arquitectura de las escuelas primarias municipales de Sevilla hasta 1937.- Kora (col.), $n^{0}$ 15.- Sevilla: Junta de Andalucía - Universidad de Sevilla, 2006.

AÑÓN ABAJAS, Rosa María: “Una obra de Sir Owen Williams: El Pioneer Health Centre en Peckham Londres, 1933-35”. En TRILLO DE LEYVA, M. (dir.) RAMOS CARRANZA, A. (coord.). Construyendo Londres, dibujando Europa. Sevilla: FIDAS/COAS, 2006.- pp. 39 a 55.

BENHE, Adolf: "La escuela de la Asociación General de Obreros Alemanes en Bernau”.- Arquitectura, № 112, Madrid, 1928.- pp. 254 a 263.

CHÂTELET, Anne Marie y LE COEUR, Marc: L'architecture scolaire. Essai d historiographie internationale.- Paris: Histoire de l'education, 2004.

DROSTE, Magdalena: Bauhaus.- Köln, Taschen, 2006.

EMERY, Marc. La “Hochschule für Gestaltung” (École supérieure de Desing), Ulm, 1955. Max Bill, architecte. En Architetture d'aujourd'hui, 321, mars, 1999.

FRAMPTON, Kenet: Estudios sobre cultura tectónica. Poéticas de la construcción en la arquitectura de los siglos XIX y XX.- Madrid: Akal ediciones, 1999.

GARCÍA, Rafael: “Jan Duiker. 1890-1935: Esbozo de una vida truncada”. Cuaderno de Notas, 2004, n. 10, p. 75

GIMMI, Karin: "Hochschule für Gestaltum, UIm”. En GIMMI, K. y otros: Max Bill Arquitecto. 2G, Revista internacional de arquitectura, 2004, n² 29-30.pp. 108-135.

GREGOTTI, Vittorio: “Complessità di Max Bill”. Casabella continuità, 1959 June, n. 228.- pp. 33-39.

GROPIUS, Walter: La nueva arquitectura y la Bauhaus. Barcelona: Lumen, 1966

HÜTTINGER, Eduard: Max Bill.- Zürich: ABC editions, 1977.

"La nuova Bauhaus di Max Bill a Ulm sul Danubio". En Architettura: cronache e storia, 1956 Jan.-Feb., v. 1, n. 5.- pp. 737-738.

LUPFER, Gilbert: Walter Gropius, 1883-1969: propagandista del nuevo diseño.- Madrid: Taschen, 2006.

MALDONADO, Tomás: Max Bill.- Buenos Aires (Argentina): Editorial Nueva Visión, 1955.

MILELLI, Gabriele: Zonnestraal, il Sanatorio di Hilversum.- Bari : Dedalo Libri, 1978.

RAMOS CARRANZA, Amadeo y AÑóN ABAJAS, Rosa María: Arquitectura y construcción: el paisaje como Argumento. Col. Ensayos para un nuevo hábitat urbano, n1.- Sevilla, UNED, 2009.

STABERG, Margit: “La scuola di Ulm”. Casabella continuità, 1962 Jan., n. 259.- pp. 2-27.

KIRSTEN, Baumann: Bauhaus Dessau: architecture design concept = architektur gestaltung idee. - Jovis Verlage GMBH, 2007

WALTERS, R. T.: "The experiment at UIm". En Architects' journal, 1959 Apr. 16, v. 129.- pp. 585-587.

WESTON, Richard: Plans, sections and elevations : key buildings of the twentieth.- London: King, 2004.

YEOMANS, David y COTTAM, David: Owen Williams,- London: Thomas Telford, 2001.

\section{Documentación gráfica}

Los dibujos de este artículo han sido realizados por Blanca del Espino Hidalgo, estudiante E.T.S. de Arquitecura de Sevilla (plan 98) y dirigidos por Rosa María Añón Abajas.

Rosa María Añón Abajas, (Sevilla, 1961), Arquitecta (1988) ETSA Sevilla, dr. Arquitecta (2001) Universidad de Sevilla. Profesora en el Departamento de Expresión Gráfica Arquitectónica (1991-1995) y desde 1995 en el Departamento de Proyectos Arquitectónicos, del que actualmente es directora. Ha participado en los programas de doctorado (2003-2006) y en el Master de Ciudad y Arquitectura Sostenible (2006-2009). Desde 2005, responsable del grupo de investigación HUM-632 “Proyecto, Progreso, Arquitectura". Profesora invitada en la FAUT Lisboa (2006 y 2007). Codirectora del Seminario Internacional "Arquitectura y construcción: el paisaje como argumento" (Sevilla, 2007). Codirectora de la colección “Ensayos para un nuevo hábitat urbano” (UNIA). Publicaciones a destacar: "La arquitectura de las escuelas primarias municipales de Sevilla hasta 1937" (2005); "Investigación e Innovación en Arquitectura. Construir el Futuro" (2006); "Una Obra de Sir Owen Willimas: el Pioneer Health Centre en Peckham, Londres, 1933-35" (2006); “Silueta Sevillana de Londres” (2006); "Arquitecturas activas" (2007); “La Construcción del Vacio” (2007); "El sur: Turismo, Servicios, Relaciones" (2007); "Confiar en la crisis" (2009); "Arquitectura y construcción: el paisaje como argumento" (2009); "Propuestas para Sevilla: de la Huerta de la Reina al Polígono Sur"(2009); "Turismo y regeneración” (2010). 